\title{
Relatedness of identities and emotional closeness with parents across and within cultures
}

\author{
E. Olcay Imamoğlu and Zahide Karakitapoğlu-Aygün ${ }^{2}$ \\ ${ }^{1}$ Department of Psychology, Middle East Technical University, Ankara, and ${ }^{2}$ Faculty of Business Administration, \\ Bilkent University, Bilkent, Ankara, Turkey
}

\begin{abstract}
Differences in emotional- and identity-relatedness with parents were explored across two cultural groups (863 university students from the USA and Turkey, representing individualist and collectivist societies, respectively) in Study 1, and across two socioeconomic status (SES) groups (353 high school students from the upper and lower SES in Turkey) in Study 2. In both studies, within-cultural differences in emotional- and identityrelatedness with parents were also explored in terms of: (i) self-directed and other-directed value orientations; and (ii) self-types, as suggested by the Balanced Integration-Differentiation Model. Results indicated cultural groups to be quite similar in emotional-relatedness, but to differ in relatedness of identities, with Turks reporting more related identities. Similarly, in Turkey, SES seemed to have more impact on identities than on emotional closeness, the lower SES adolescents reporting more relatedness with parents than upper SES adolescents. Thus, relatedness of identities appeared to be more important than emotional relatedness in differentiating between cultural and SES contexts. Results involving different self-types and value orientations pointed to both crosscultural similarities and within-cultural diversity in the two domains of relatedness. Theoretical implications of cross- and within-culture differences in emotional- and identity-relatedness with parents are discussed.
\end{abstract}

Key words: Balanced Integration-Differentiation Model, cultural and socioeconomic status differences, individualism-collectivism, relatedness with parents, self-types.

\section{Introduction}

The attachment literature indicates emotional relatedness with parents or primary caregivers to be a universal phenomenon (Ainsworth, 1972; Bowlby, 1988; Van Ijzendoorn \& Sagi, 1999). Studies from the cross-cultural literature have also provided evidence pointing to cross-cultural similarities in emotional closeness with parents (Georgas et al., 2001). However, the cross-cultural literature within the individualism-collectivism (I-C) framework indicates that there are cultural differences in how related or separated people construe themselves. Accordingly, individuals from the collectivist cultures are characterized as more related and interdependent, whereas those from the individualist cultures are characterized as being more separate and inde-

Correspondence: E. Olcay Imamoğlu, Department of Psychology, Middle East Technical University, 06531 Ankara, Turkey. Email: eolcay@metu.edu.tr

The present paper is based on an extended analysis of the data collected as part of a doctoral study conducted by the second author under the supervision of the first. The data used in the present studies are a part of a larger database used in another paper (Imamoğlu, E. O. and Karakitapoğlu-Aygün, Z. (2006). Actual, ideal, and expected relatedness with parents across and within cultures. European Journal of Social Psychology, 36, 721-745) which tackles a different theoretical issue.

Received 30 October 2005; accepted 30 December 2006. pendent from others (Markus \& Kitayama, 1991; Triandis, 1995). Thus, as considered more fully later in the paper, there seems to be some ambiguity in the cross-cultural literature concerning the exact role of relatedness, particularly with parents.

Our aim in the two studies reported in the present paper was to shed light on this issue by exploring how context, person, and domain-related variables influence relatedness with parents. That is, we tried to address the question of the degree to which perceptions of relatedness with parents vary depending on the I-C nature of contexts, the self-types or value orientations of persons studied, as well as the particular domain of relatedness measured. Accordingly, we explored both cross-cultural and within-cultural differences in two domains of perceived relatedness with parents: emotional relatedness and relatedness of identities. The former domain was understood as reflecting perceived affective overlap (i.e. the degree to which youngsters perceive themselves and their parents as emotionally separate from each other or in affective unison with each other). In contrast, the latter domain was considered to tap the degree to which youngsters perceive themselves and their parents as distinct or overlapping entities. Our cross-cultural comparisons involved Turkey and the USA, cultures specified as collectivistic and individualistic, respectively (Hofstede, 1980). We explored within-culture variations in the two domains of relatedness with parents in terms of differences involving: (i) self-types (i.e. whether individuals with 
different self-types differ in emotional- and identityrelatedness with parents within each culture, and show similar patterns of relatedness across cultures); (ii) selfdirected and other-directed value orientations (i.e. whether individuals with different value orientations vary in their reports of the two domains of relatedness with parents within each culture, and in a similar fashion across cultures); and (iii) socioeconomic status (SES) differences (upper, lower) in Turkey (i.e. whether individuals from different SES groups vary in their reports of the two domains of relatedness with parents). In the second study involving SES differences in Turkey, we also considered within-SES variation in relatedness with parents involving different self-types and value orientations.

Our interest in studying within-culture variations, apart from cross-cultural differences, was based on the idea that cultures often tend not to be as homogeneous as they are assumed to be. In recent years, several psychologists have been critical of treating cultural differences as inherent trait-like qualities of people belonging to a particular society, and have stressed the need to pay more attention to within-culture variations (Sinha \& Tripathi, 1994; Matsumoto, 1999; Takano \& Osaka, 1999; Bandura, 2001; Imamoğlu, 2003; Neff, 2003; Imamoğlu \& KarakitapoğluAygün, 2006). For example, although people from a relatively collectivistic culture are assumed to be more related than those from an individualistic one (Triandis, 1995), people living within a particular culture often may vary in the degree to which they internalize the culture's outlook. Interaction of cultural, social structural and personality systems may be involved in the degree to which inhabitants internalize the culture's outlook (Geertz, 1973a,b).

As noted above, we aimed to explore how emotional- and identity-relatedness with parents vary depending on not only culture but also SES, self-types, and value orientations of individuals. Accordingly, we considered SES as a possible source of social structural within-culture variation (in the second study) because, as noted later in the paper, the upper social classes, in all societies and cultures, are likely to be more individualistic than the lower social classes (Triandis, 1989, 1995). Second, we considered self-type as a possible source of person-related within-culture variation because recent studies, based on the Balanced Integration and Differentiation (BID) model (Imamoğlu, 1995, 1998, 2003), have systematically identified four self-types in Turkey, Canada, and the USA. (Imamoğlu, 1998, 2003; Kurt, 2002a,b; Güler, 2004; Imamoğlu \& KarakitapoğluAygün, 2004; Imamoğlu, S., 2005). Therefore, when exploring the impact of self-types on the two domains of relatedness with parents, we also used the four self-types, specified by the BID model, as explained later in the paper. Finally, our interest in considering the role of self- or otherdirected values, as possible sources of person-related within-culture variation, was based on the literature which indicates that self/other focus seems to constitute an important dimension of I-C (Triandis, 1989; Markus \& Kitayama, 1991; Singelis, 1994). A collectivist orientation has been associated with valuing other-directed values (e.g. being obedient and devout to parents), whereas an individualist orientation has been associated with favouring a selfdirected outlook (e.g. choosing own goals, independence). In the following sections, in line with Triandis's (1995) suggestion, we refer to respondents with self-directed value orientations as idiocentric, and those with other-directed value orientations as allocentric, whereas we use I-C to refer to contextual differences (e.g. between Turkey and the USA or between upper and lower SES) in relatedness with parents. Below, the BID model, used to specify different self-types, is briefly explained and then the expectations of the first study are reported.

\section{Balanced Integration and Differentiation model}

The BID model (Imamoğlu, 1995, 1998, 2003) is based on the premise that 'the natural order involves a balanced system resulting from the interdependent integration of differentiated components' (Imamoğlu, 2003; p. 371). Human beings, as parts of this natural system are assumed to have natural propensities for both intrapersonal differentiation (i.e. a self-developmental tendency to actualize one's unique potentials and be effective; coined as intrapersonal to highlight that it is not a process that happens from others, as is usually understood, but one that involves an intrinsic exploration), and interpersonal integration (i.e. an interrelational tendency to feel connected to others), which represents distinct and complementary processes of a balanced self-system. The low and high ends of the latter orientation are labelled as separatedness and relatedness, respectively. The high end of the former orientation is referred to as individuation (i.e. developing one's potential with a genuine intrinsic frame of reference, such as personal capabilities, inclinations, free will or willful consent), while the low end is referred to as normative patterning (i.e. developing one's potential in accordance with extrinsic referents, such as normative expectations and social control).

Thus, the BID model differs from the bipolar selfconstrual formulations within the I-C framework, noted above (Markus \& Kitayama, 1991), which tend to confound the relational and individuational orientations of individuals (e.g. assuming that independence or individuation necessarily implies separation; see Imamoğlu, 2003 for a related discussion). As defined in the BID model, 'individuation is considered as a process that happens not from others but within oneself and, in fact, would be better if it happens with positive feelings of being related with others. The reason for the latter argument is that when relatedness 
and individuation can find mutual satisfaction in a balanced state, they tend to complement one another. .' (Imamoğlu, 2003; p. 378). Furthermore, individuation and relatedness, as considered by the BID model, should not be equated with I-C, respectively, because the latter dimensions refer to highly global constructs of world views, encompassing multiple components (Oyserman, Coon, \& Kemmelmeier, 2002). Although not equivalent, individuation may be expected to be associated with those components of individualism that focus on reliance on internal referents (but not in terms of being separate), whereas relatedness may be considered to be associated with those aspects of collectivism concerned with being related with others and valuing affectionate ties with family and significant others (but not being conforming or group bound), as suggested by recent studies (Imamoğlu \& Karakitapoğlu-Aygün, 2004; Imamoğlu \& Kurt, unpubl. data, 2004).

Thus, because the BID model maintains that differentiation (toward individuation) and integration (toward relatedness) are distinct orientations, one can be high or low on each orientation, the combinations of which are suggested to give rise to four self-types as follows: separatedindividuation, related-patterning (representing the most differentiated and integrated self-types, respectively), separated-patterning and related-individuation (representing the most unbalanced and balanced types, respectively, because a balanced self-system requires that the needs for both relatedness and individuation be satisfied). The model assumes that, in general, the basic pattern of psychological functioning associated with these different self-types may be expected to be quite similar across cultures.

The BID model is supported by studies that challenge the assumption that individuation and relatedness are opposites (Imamoğlu, 1987; Ryan \& Lynch, 1989; Li, 2002; Oyserman et al., 2002), as well as by the literature on attachment theory (Ainsworth, 1972; Bowlby, 1988), selfdetermination theory (Ryan, 1991; Ryan \& Deci, 2000), and tends to be generally congruent with many other theoretical outlooks, which, in one way or other, have emphasized the importance of both relatedness and individuation or autonomy, as basic needs (e.g. Kağıtçıbaşı's [1996, 2005] autonomous-related self model). However, a theoretical discussion of those different outlooks is beyond the limits of this paper (see Imamoğlu, 2003; also Markus \& Kitayama, 2003; Miller, 2003; for related reviews). Also, in direct tests of the model by using the BID scale, which is described later in the paper, investigators have demonstrated that individuation and relatedness are distinct orientations, and have demonstrated the existence of four distinct self-types among Turkish, American, and Canadian samples (Imamoğlu, 1998, 2003, 2006; Kurt, 2002a,b; Gezici \& Güvenç, 2003; Güler, 2004; Imamoğlu \& Karakitapoğlu-Aygün, 2004, 2006; Imamoğlu, 2005). Furthermore, as predicted by the model, relatedness and individuation were found to be associated with qualitatively distinct and complementary domains of variables (e.g. relatedness with such affective-relational variables as perceived love-acceptance, self and family satisfaction, positive self- and other models, secure attachment, trust for self, positive future expectations, and low trait anxiety), whereas individuation was found to be related with intrinsic motivational variables such as the need for cognition, need for exploration, curiosity, and tolerance for ambiguity (Imamoğlu EO, 2003, 2006; Imamoğlu S, 2005; Imamoğlu \& Imamoğlu, in press). Expectations of the present study involving relatedness with parents as perceived by respondents with different self-types, suggested by the BID model, and with different value orientations are explained below.

\section{Study 1: Perceived relatedness of identities and emotional closeness with parents in Turkey and the USA}

\section{Cultural differences}

Individualism-collectivism differentiation has been a basic dimension in exploring cross-cultural differences in relatedness. As noted above, the related literature indicates Turkey and the USA to represent collectivist and individualist cultures, respectively (Hofstede, 1980). In accordance with the I-C framework, the Turkish context has been traditionally characterized by an emphasis on interpersonal relationships and close ties with family and relatives encouraging higher levels of relatedness than, for instance, the Swedes (Imamoğlu \& Imamoğlu, 1992; Imamoğlu et al. 1993). Furthermore, when asked about their desired levels of relatedness, Turkish people consistently report favouring even more relatedness with family members and neighbours (Imamoğlu, 1987, 2002; Imamoğlu \& Imamoğlu, 1996). However, people from the individualistic American culture are generally characterized as being less related than those from the more collectivistic Asian cultures (Triandis et al., 1988; Uleman et al., 2000). Thus, on the basis of those studies, regardless of domain, Turkish respondents may be expected to report more relatedness with their parents than the Americans.

However, there seems to be some conflicting evidence regarding cultural differences in relatedness; for instance, regarding relationality in the USA, some investigators (Kashima et al., 1995; Cross, Bacon, \& Morris, 2000; Oyserman et al., 2002) concluded that Americans tend to be relational in terms of being close to their families and groups, though not in terms of feeling obligated or duty bound. Similarly, Cross et al. (2000) noted that people who have high, rather than low, levels of relational interdependent selves, characteristic of the American type 
of interdependent self, were more likely to rate their important relationships as close, to show more commitment to their relationships and to consider the needs of others in their decisions. Furthermore, a recent study involving 16 cultures (including Turkey and the USA) indicated that respondents from all countries showed close emotional bonds with mothers, fathers, and siblings, with only minor differences across cultural groups (Georgas et al., 2001). Other investigators have also concluded that patterns of emotional closeness do not differ systematically across cultures (Fijneman, Willemsen, \& Poortinga, 1996; Van den Heuvel \& Poortinga, 1999; Imamoğlu \& Karakitapoğlu-Aygün, 2004). In a similar vein, as noted before, the attachment literature also indicates emotional relatedness with parents or primary caregivers to be a universal phenomenon (Ainsworth, 1972; Bowlby, 1988). Thus, on the basis of the above-noted studies, we expected Turkish and American respondents to be quite similar in emotional closeness with parents. However, in view of their respective differences in collectivist and individualist traditions, we expected Turks to report more relatedness involving identities than Americans. Hence, we expected crosscultural differences in terms of identity-relatedness to be greater than those in emotional-relatedness with parents. In these predictions, our idea was that culture's impact on emotional closeness with parents might be much less than that on social norms or expectations as to whether identities should be distinct or related (Imamoğlu \& KarakitapoğluAygün, 2006).

In both societies, we expected to find similar patterns of variability in relatedness with parents depending on selftypes and value orientations of respondents. Specifically, because the relational self-orientation, as proposed by the BID model, has been found to represent the affective domain (Imamoğlu, 2003; Imamoğlu, 2005), we expected respondents with related rather than separated self-types to report more emotional closeness with their parents regardless of their level of individuation in both cultures. In contrast, we expected respondents with individuated rather than patterned self-types to report less related identities with parents regardless of culture. Hence, respondents with related-patterned self-types (i.e. the most integrated type) were expected to report more overlapping identities with their parents than respondents with separated-individuated or the most differentiated self-type. In terms of value orientations, in both cultures, we expected the other-directed value orientation to be positively associated with perceived relatedness in both domains, while the self-directed orientation to be associated only with having distinct or related identities and not with emotional closeness in accordance with past findings (Georgas et al., 2001). No culturespecific predictions were made regarding the associations between relatedness judgments and endorsement of values apart from the general expectations noted above.

\section{Gender differences}

Gender-related expectations and social roles might play an important role in perceptions of relatedness. According to research conducted in the USA (Gilligan, 1982; Lykes, 1985; Mellor, 1989; Olver et al., 1989; Cross \& Madson, 1997; Gabriel \& Gardner, 1999), generally, men are more likely to perceive themselves as less related but more independent. Females, however, are more likely to emphasize relatedness and embeddedness with others, especially with their mothers (Jordan, 1997).

In a similar vein, Sunar (1999) found that Turkish female adolescents attributed more importance to interpersonal characteristics and reported greater satisfaction with regard to these interpersonal attributes than their male counterparts. In more recent studies, well-educated Turkish women were found to be both more related, and more individuated than Turkish men (Imamoğlu, 2002, 2003; Kurt, 2002a; Imamoğlu \& Karakitapoğlu-Aygün, 2004). In light of these findings, female respondents were expected to report more relatedness with their parents, and especially with their mothers, as compared to male respondents in both cultural groups.

\section{Method}

Participants. Eight hundred and sixty-three Turkish and American university students participated in the study, as explained below.

American (US) sample: A sample of 441 University of Michigan undergraduates (186 male, 255 female) taking introductory psychology courses participated in the study to fulfil a course requirement. The mean age of the sample was 18.88 years $(S D=0.97)$, ranging from 18 to 24 years. The sample was predominantly Euro-American, with $81 \%$ identifying as Euro-American, 9.9\% as Asian-American, $5.7 \%$ as African-American, and $3.4 \%$ other. ${ }^{1}$

Turkish sample: The Turkish sample consisted of 422 undergraduate students (185 male, 237 female) from different departments of two universities in Ankara. In terms of parental education, most of the respondents from both universities were from middle and upper middle SES families. The mean age of the sample was 19.75 years, $(S D=1.84)$, ranging from 17 to 25 years.

The Turkish and the US samples were generally comparable in terms of gender and age, but not in terms of parental education. The education level of the US parents was somewhat higher than that of the Turkish sample (mean level of total years of education $=16.88, S D=2.52$ for the US parents; and $M=10.84, S D=3.97$ for Turkish parents). Therefore, as noted later, parental education was statistically controlled while investigating cross-cultural differences. 
Measures and procedure. Questionnaires were group administered to students together with other scales not considered in the present paper. The Turkish and English versions of the scales, checked through back-translations, were used as described below. Two native speakers of English and Turkish also checked the scales for wording, accuracy, and clarity of items in both languages.

All respondents filled out the questionnaires in class. A one-point bonus was given to the students for their participation, which was on a voluntary basis. The participants were assured that their responses would be anonymous and confidential.

Perceived Relatedness Scale: The measure of perceived relatedness was based on a modification of Aron et al.'s (1991, 1992) interpersonal closeness scale. Following Aron et al., relatedness was defined as inclusion of the mother and the father in the self-concept. Relatedness was measured in two domains: emotional closeness, and relatedness (vs distinctness) of identity. Emotional closeness was defined as the perceived degree of affective closeness with parents, and was measured by the following questions: 'Which of the drawings best describes your affective relationship with your mother/father?', 'How would you wish your relationship with your mother/father to be?', 'In your opinion, how does your mother/father expect your relationship to be?'. In contrast, relatedness of identity was defined as the degree to which youngsters have distinct or overlapping identities with regard to their parents, and was measured by the following questions: 'To what extent do you perceive yourself as an independent and distinct individual from your mother/father?', 'To what extent do you wish to be an independent and distinct individual from your mother/father?', 'In your opinion, to what extent does your mother/father expect you to be an independent and distinct individual from her/him?'. All the items were measured via the Venn-like diagrams (two circles - labelled 'me' and 'mom' or 'dad' - with increasing degrees of overlap) whose response options changed between 1 (no-overlap between circles) and 9 (total overlap between circles). High scores on the scale denote being more related (i.e. more emotional closeness, and more related identities).

The reliability and validity of the scale were tested in a pilot study involving 125 Turkish university students. The respective Cronbach's alpha values in relation to mothers and fathers were 0.85 and 0.78 for emotional closeness and 0.75 and 0.75 for related identities, respectively. Validity checks with the question 'To what extent does your mother/ father constitute an important part of your sense of who you are?' yielded acceptable construct validity (correlations varying between 0.52 and 0.62 ) for the domains of relatedness with mothers and fathers.

Furthermore, to get an idea about the suitability of the Perceived Relatedness Scale (PRS) to the present crosscultural purposes, we tested its factor structure by using multigroup confirmatory factor analysis. Three questions for each domain of relatedness (i.e. emotional relatedness, identity-relatedness) were considered as indicators. Overall, a two-factor model revealed acceptable fit, $\chi^{2}$ (17, $N=855)=158.64$, goodness of fit index $=0.93$, comparative fit index $=0.94$. As can be seen in Table 1, Cronbach's alpha values were also satisfactory for both cultural groups in the present study (as well as the SES groups of the second study).

Table 1 Means, standard deviations, alpha and $F$ values for relatedness with parents involving cultural and SES data

\begin{tabular}{|c|c|c|c|c|c|c|c|c|c|}
\hline \multirow[b]{2}{*}{ Culture $^{\dagger}$} & \multicolumn{3}{|c|}{ Turkey } & \multicolumn{3}{|c|}{ USA } & \multirow[b]{2}{*}{$F^{\dot{\phi}}$} & \multirow[b]{2}{*}{$M S E$} & \multirow[b]{2}{*}{$\eta^{2}$} \\
\hline & $\alpha$ & $M$ & $S D$ & $\alpha$ & $M$ & $S D$ & & & \\
\hline General relatedness & 0.84 & 5.85 & 1.16 & 0.87 & 5.38 & 1.09 & $20.64 * * *$ & 1.26 & 0.02 \\
\hline Emotional & 0.78 & 6.92 & 1.19 & 0.84 & 6.71 & 1.20 & $4.29 *$ & 1.43 & 0.01 \\
\hline \multirow[t]{2}{*}{ Identity } & 0.83 & 4.77 & 1.53 & 0.88 & 4.03 & 1.41 & $27.80 * * *$ & 2.15 & 0.03 \\
\hline & \multicolumn{3}{|c|}{ Upper SES } & \multicolumn{3}{|c|}{ Lower SES } & & & \\
\hline SES & $\alpha$ & $M$ & $S D$ & $\alpha$ & $M$ & $S D$ & $F^{\S}$ & $M S E$ & $\eta^{2}$ \\
\hline General relatedness & 0.87 & 6.07 & 1.39 & 0.83 & 6.88 & 1.36 & $29.88 * * *$ & 1.89 & 0.08 \\
\hline Emotional & 0.83 & 7.00 & 1.40 & 0.74 & 7.43 & 1.55 & $6.53^{*}$ & 2.17 & 0.02 \\
\hline Identity & 0.87 & 5.14 & 1.75 & 0.82 & 6.34 & 1.80 & $40.20 * * *$ & 3.16 & 0.10 \\
\hline
\end{tabular}

$* p<0.05, * * * p<0.001$

${ }^{\dagger}$ Means are corrected for parental education.

Degrees of freedom $=1$ and 853 .

${ }^{\S}$ Degrees of freedom $=1$ and 351 .

SES, socioeconomic status. 
Self-directed and other-directed value orientations: In line with the related literature (Triandis, 1995), 14 values were selected from Schwartz's (1992) Value Survey, half of which represented self-directedness and the rest, otherdirectedness. Self-directed values (i.e. freedom, creativity, independent, curious, capable, choosing own goals, and self-respect), represented an idiocentric orientation of attending to the needs and goals of the self rather than the needs of others and were mainly concerned with Schwartz et al.'s (2001) self-direction domain, whereas otherdirected values (i.e. honouring of parents and elders, obedient, helpful, devout, reciprocation of favours, respect for tradition, and family security), represented an allocentric orientation of attending to the needs and wishes of others and were concerned with the conformity, benevolence, and traditionalism domains according to Schwartz et al. (2001).

Respondents rated the importance of each value as a guiding principle in their lives on a five-point scale $(1=$ not important at all and $5=$ very important). Separate factor analyses indicated the self-directed and other-directed values to be loaded under two separate factors for each cultural (and SES) group, except that in the analysis of the US (and lower SES) data, the weakest item loaded under both factors. For the Turkish university student sample, Cronbach's alpha values were 0.73 and 0.75 , and for the American sample 0.75 and 0.71 for self-directed and otherdirected values, respectively.

Balanced Integration-Differentiation Scale: This self scale (Imamoğlu, 1998, 2003) consists of two subscales. The Self-Developmental Orientation subscale, consisting of 13 items, is concerned with intrapersonal differentiation toward individuation (i.e. relying on one's inner qualities and interests as a developmental frame of reference rather than accommodating oneself to a normative frame of reference). Sample items are: 'It is important for me that I develop my potential and characteristics and be a unique person' and the reverse-scored item, 'I feel it is more important for everyone to behave in accordance with societal expectations rather than striving to develop his/her uniqueness'. The 16-item Interrelational Orientation subscale aimed to measure tendencies and preferences for relatedness and connectedness with family and others. Sample items are: 'I emotionally feel very close to my family' and the reverse-scored item of, 'I feel emotionally alienated from my close environment'. Participants were asked to indicate their degree of agreement with the items using five-point scales ranging from 1 (not at all) to 5 (very). Cronbach's alpha values were reported to vary between 0.74 and 0.82 for the former and between 0.80 and 0.91 for the latter subscales in different studies (Imamoğlu, 1998, 2003; Kurt, 2002a; Gezici \& Güvenç, 2003; Güler, 2004). Test-retest reliabilities of the subscales, over a period of 3 weeks, were found to be 0.85 and 0.84 , respectively (Güler,
2004). The scale was found to have good convergent and discriminant validity (Imamoğlu, 2002). Mean scores on these subscales were used to measure individuational and relational self-orientations. As noted above, combinations of high and low scores on these two subscales yield four self-construal types (i.e. separated-individuated, relatedpatterned types representing the most differentiated and most integrated types, respectively; and separatedpatterned and related-individuated types representing the most unbalanced and balanced types, respectively; for further explanation see Imamoğlu, 1998, 2003).

\section{Results and discussion}

In cross-cultural analyses reported below, parental education was included as a covariate because there were some weak correlations between parental education and relatedness measures in our samples. As sample sizes were large for both cultural groups, the more conservative 0.01 level of significance was accepted. In all follow-up analyses, Tukey's technique was used for within-subject effects and univariate analysis of covariance was used for betweensubject effects.

Cross-cultural differences in domains of relatedness with parents. To explore cross-cultural and gender differences in the two domains of relatedness, a 2 (culture: Turkey, USA) $\times 2$ (gender: male, female) $\times 2$ (parent: mother, father) $\times 2$ (domain of relatedness: emotional-relatedness, identity-relatedness) analysis of covariance (ANCOVA) with repeated measures on the last two variables was conducted. Main effects involving culture, $F_{1,825}=20.74, M S E=4.99$, $p<0.001, \eta^{2}=0.03$, parent, $F_{1,825}=47.87, M S E=1.31$, $p<0.001, \quad \eta^{2}=0.06$, and domain of relatedness, $F_{1,825}=111.78, M S E=2.10, p<0.001, \eta^{2}=0.12$ reached significance. Accordingly, Turkish respondents $(M=5.85)$ endorsed more relatedness with their parents than did the US respondents $(M=5.37)$. All participants reported greater relatedness with their mothers $(M=5.92)$ as compared to fathers $(M=5.30)$. As for the domain of relatedness, all participants reported more relatedness in the emotional $(M=6.81)$ than in the identity domain $(M=4.40)$. However, these main effects were qualified by significant interactions as explained below.

First, culture $\times$ domain of relatedness was significant, $F_{1,825}=14.68, M S E=2.10, p<0.001, \eta^{2}=0.02$. As shown in Table 1, the Turkish and American students did not differ significantly in emotional closeness at the accepted 0.01 level (although there was a trend at the 0.05 level for Turks to be more related emotionally), but Turks seemed to have significantly more related identities than Americans.

Thus, in both Turkey and the USA, respondents reported more emotional- than identity-relatedness. Furthermore, as expected, Turkish and American respondents did not differ 
Table 2 Gender differences in relatedness with parents in cross-cultural and SES studies

Cross-cultural study ${ }^{\dagger}$

\begin{tabular}{|c|c|c|c|c|c|c|c|}
\hline & \multicolumn{2}{|c|}{ Women } & \multicolumn{2}{|c|}{ Men } & \multirow[b]{2}{*}{$F^{\dot{\dagger}}$} & \multirow[b]{2}{*}{$M S E$} & \multirow[b]{2}{*}{$\eta^{2}$} \\
\hline & $M$ & $S D$ & $M$ & $S D$ & & & \\
\hline Relatedness with mothers & 6.06 & 1.15 & 5.77 & 1.21 & $12.67 * * *$ & 1.31 & 0.02 \\
\hline Relatedness with fathers & 5.27 & 1.37 & 5.33 & 1.43 & 0.29 & 1.92 & 0.00 \\
\hline
\end{tabular}

SES study

\begin{tabular}{|c|c|c|c|c|c|c|c|}
\hline & \multicolumn{2}{|c|}{ Men } & \multicolumn{2}{|c|}{ Women } & \multirow[b]{2}{*}{$F^{\S}$} & \multirow[b]{2}{*}{$M S E$} & \multirow[b]{2}{*}{$\eta^{2}$} \\
\hline & $M$ & $S D$ & $M$ & $S D$ & & & \\
\hline Relatedness with mothers & 6.91 & 1.49 & 6.40 & 1.40 & $7.71 * *$ & 2.10 & 0.02 \\
\hline Relatedness with fathers & 6.33 & 1.81 & 6.28 & 1.63 & 0.05 & 2.99 & 0.00 \\
\hline
\end{tabular}

$* * p<0.01, * * * p<0.001$.

${ }^{\dagger}$ Means are corrected for parental education.

Degrees of freedom $=1$ and 830-850.

${ }^{\S}$ Degrees of freedom $=1$ and $351-352$.

SES, socioeconomic status.

from each other in emotional closeness with either parent; however, compared to Americans, Turkish students reported having more related identities with their parents. Hence, our results imply that this latter identity-domain may be more differentiative of samples from collectivistic or individualistic contexts than the emotional closeness domain.

Second, gender of the respondent-parent interaction was found to be significant, $F_{1,825}=18.36, \quad M S E=1.31$, $p<0.001, \eta^{2}=0.02$. As shown in Table 2, there were no differences between men and women on perceived relatedness with fathers, but on relatedness with mothers to which women assigned higher scores than men. This interaction was independent of the domain of relatedness. Thus, as expected, women reported more overall relatedness with mothers than did men. This finding is in line with the previously reported studies indicating women to be more interrelated in their relationships, especially with mothers (Chodorow, 1978; Gilligan, 1982; Lykes, 1985; Youniss \& Ketterlinus, 1987; Frank et al., 1988; Jordan, 1997). In contrast, no gender differences were observed for relatedness with fathers. However, these gender differences, although pervasive over culture and domain of relatedness, were rather weak.

As culture-related effects have already been discussed above, only the effects involving self-types and value orientations are considered below.

Relatedness-domain differences involving self-types within and across cultures. As noted above, four self-types, specified by the BID model, were created using medians as cut-off points on the overall data (involving both cultures) from the two subscales of the BID scale. Then, to explore the impact of culture and self-types on domains of relatedness with parents, a 2 (culture: Turkey, USA) $\times 4$ (self-type: separated-patterned, separated-individuated, relatedpatterned, related-individuated) multivariate analysis of covariance (MANCOVA), using emotional-relatedness and identity-relatedness as dependent variables, was conducted. The multivariate self-type effect was found to be significant, $F_{6,1688}=30.42, p<0.001, \eta^{2}=0.10$. As shown in Table 3, both univariate self-type effects were significant. Accordingly, students with related self-types (i.e. both relatedpatterned and related-individuated types) reported more emotional closeness with their parents as compared to those with separated self-types (i.e. both separated-patterned and separated-individuated types). In terms of identities, students with related-patterned self-types appeared to be most related; the separated-individuated students appeared the least related; whereas the other two groups were in between.

Thus, in both cultures, consistent trends were obtained in relatedness perceptions of respondents with different selftypes, as specified by the BID model. Independent of culture, individuals with related self-types, regardless of their level of individuation, reported more emotional closeness with parents than those with separated self-types. As expected, it is implied that emotional closeness with parents tends to be associated only with the relational selforientation, independently of the individuational orientation. However, perceiving one's identity as related with parents seemed to involve both relational and individuational self-orientations. In both cultures, the relatedpatterned respondents (representing the most integrated 


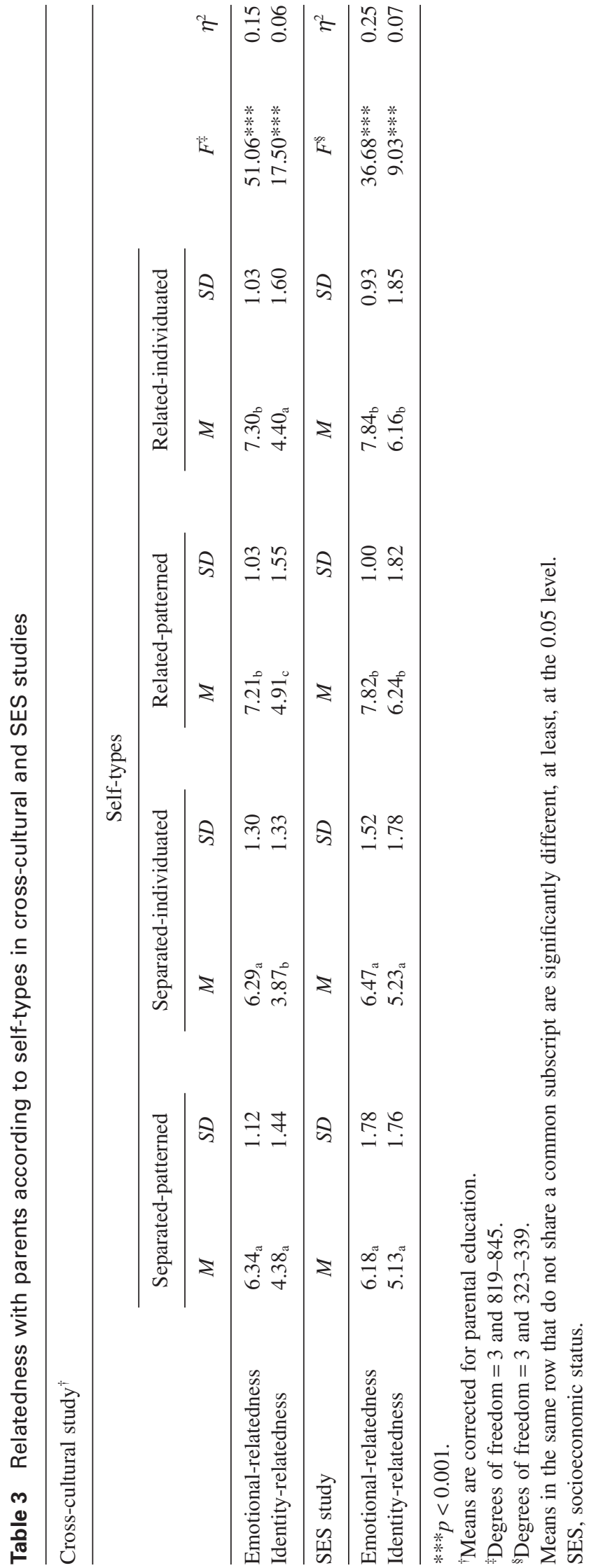

self-type) perceived their identities as most related with parents. In contrast, the separated-individuated respondents (representing the most differentiated self-type) perceived their identities as least related with parents, whereas the other two self-types (i.e. related-individuated and separated-patterned) were in-between. Not only were these effects independent of culture, but the impact of self-types on relatedness with parents was much greater than that of culture, especially for emotional closeness.

Relatedness-domain differences involving value-orientations within and across cultures. To explore whether the impact of self-directed or other-directed value orientations on relatedness with parents differed within and across cultures, first, high and low idiocentric and allocentric groups were created by using medians of value orientations as cutting points; then, a 2 (culture: Turkey, USA) $\times 2$ (idiocentric values: low, high) $\times 2$ (allocentric values: low, high) MANCOVA was conducted on the two domains of relatedness. Multivariate effects for both the allocentric value orientation, $F_{2,836}=46.92, p<0.001, \eta^{2}=0.10$, and idiocentric value orientation, $F_{2,836}=15.07, p<0.001$, $\eta^{2}=0.04$, were found to be significant. As shown in Table 4, univariate effects involving both identity and emotional closeness were significant for the allocentric value orientation. Accordingly, respondents high in allocentric orientation reported being both more close to their parents as well as having more related identities than those low in allocentric value orientation. However, the univariate effect involving idiocentric orientation reached significance only for identity and showed a trend at the 0.02 level of significance for emotional closeness. As shown in Table 4, respondents high in idiocentric value orientation reported having less related identities than the low idiocentric respondents; in contrast, the high idiocentric respondents showed a weak trend to be more emotionally close to their parents than the low idiocentric respondents. However, impact factors of the effects involving idiocentric value orientation were much lower than those for the allocentric orientation (Table 4). The fact that these effects did not interact with culture implied that they were valid for both cultures.

Thus, within each society the more allocentric students (in terms of endorsing other-directed values) appeared to report more relatedness with parents in both domains than those less so. However, in both societies, the more, rather than the less, idiocentric students (in terms of endorsing self-directed values) tended to perceive their identities as relatively less related with their parents but showed a weak trend to be closer to them emotionally. Thus, when parents are targeted, regardless of culture, allocentric values seem to be associated with both emotional- and identityrelatedness, whereas idiocentric values, significantly but weakly, seem to be associated only with relatively less related identities. 
Table 4 Mean relatedness with parents for high/low idiocentric and allocentric groups involving cross-cultural and SES studies

$$
\text { Cross-cultural study }{ }^{\dagger}
$$

\begin{tabular}{|c|c|c|c|c|c|c|c|}
\hline & \multicolumn{4}{|c|}{ Idiocentric value orientation } & \multirow[b]{3}{*}{$M S E$} & \multirow[b]{3}{*}{$F^{\ddagger}$} & \multirow[b]{3}{*}{$\eta^{2}$} \\
\hline & \multicolumn{2}{|c|}{ High } & \multicolumn{2}{|c|}{ Low } & & & \\
\hline & $M$ & $S D$ & $M$ & $S D$ & & & \\
\hline Emotional-relatedness & 6.89 & 1.22 & 6.70 & 1.17 & 1.33 & $5.35^{*}$ & 0.01 \\
\hline Identity-relatedness & 4.24 & 1.55 & 4.60 & 1.48 & 1.96 & $13.56 * * *$ & 0.02 \\
\hline
\end{tabular}

Allocentric value orientation

\begin{tabular}{|c|c|c|c|c|c|c|c|}
\hline & \multicolumn{2}{|c|}{ High } & \multicolumn{2}{|c|}{ Low } & \multirow[b]{2}{*}{$M S E$} & \multirow[b]{2}{*}{$F^{\dot{\phi}}$} & \multirow[b]{2}{*}{$\eta^{2}$} \\
\hline & $M$ & $S D$ & $M$ & $S D$ & & & \\
\hline Emotional-relatedness & 7.11 & 1.11 & 6.48 & 1.22 & 1.33 & $59.77 * * *$ & 0.07 \\
\hline Identity-relatedness & 4.84 & 1.56 & 4.00 & 1.40 & 1.96 & $73.22 * * *$ & 0.08 \\
\hline
\end{tabular}

\begin{tabular}{|c|c|c|c|c|c|c|c|}
\hline & \multicolumn{4}{|c|}{ Idiocentric value orientation } & \multirow[b]{3}{*}{$M S E$} & \multirow[b]{3}{*}{$F^{\S}$} & \multirow[b]{3}{*}{$\eta^{2}$} \\
\hline & \multicolumn{2}{|c|}{ High } & \multicolumn{2}{|c|}{ Low } & & & \\
\hline & $M$ & $S D$ & $M$ & $S D$ & & & \\
\hline Emotional-relatedness & 7.38 & 1.38 & 7.14 & 1.62 & 2.00 & 1.37 & 0.00 \\
\hline Identity-relatedness & 5.80 & 1.93 & 5.83 & 1.79 & 2.97 & 0.01 & 0.00 \\
\hline
\end{tabular}

Allocentric value orientation

\begin{tabular}{|c|c|c|c|c|c|c|c|}
\hline & \multirow{2}{*}{\multicolumn{2}{|c|}{ High }} & \multirow{2}{*}{\multicolumn{2}{|c|}{ Low }} & \multirow[b]{3}{*}{$M S E$} & \multirow[b]{3}{*}{$F^{\S}$} & \multirow[b]{3}{*}{$\eta^{2}$} \\
\hline & & & & & & & \\
\hline & $M$ & $S D$ & $M$ & $S D$ & & & \\
\hline Emotional-relatedness & 7.71 & 1.17 & 6.81 & 1.64 & 2.00 & $18.44 * * *$ & 0.05 \\
\hline Identity-relatedness & 6.30 & 1.64 & 5.34 & 1.84 & 2.97 & $14.17 * * *$ & 0.04 \\
\hline
\end{tabular}

$* p<0.05, * * * p<0.001$.

${ }^{\dagger}$ Means are corrected for parental education.

Degrees of freedom $=1$ and 837 .

${ }^{\S}$ Degrees of freedom $=1$ and 324 .

SES, socioeconomic status.

Overall analysis of key variables. The overall pattern of relationships between key variables was tested using structural equation modelling (SEM) analysis, as shown in Figure 1 (see Table 5 for correlations among the variables). ${ }^{2}$ Using LISREL, allocentrism, culture, individuation, idiocentrism and relatedness (of self-construals) significantly predicted identity-relatedness; in contrast, only relatedness and allocentrism predicted emotional relatedness, $\chi^{2}(3, N=842)=16.43, p<0.001$, Goodness of Fit Index $(\mathrm{GFI})=0.99$, Adjusted Goodness of Fit Index $(\mathrm{AGFI})=0.95$, Comparative Fit Index $(\mathrm{CFI})=0.99$. Thus, an allocentric value orientation seems to be the best predic- tor of identity-relatedness with parents, whereas a relational self-orientation seems to be the best predictor of emotionalrelatedness with parents in both cultures.

\section{Study 2: Perceived relatedness of identities and emotional closeness with parents at the upper and lower SES in Turkey}

As noted earlier, in this second study we aimed to explore SES-related differences in Turkey regarding the considered 


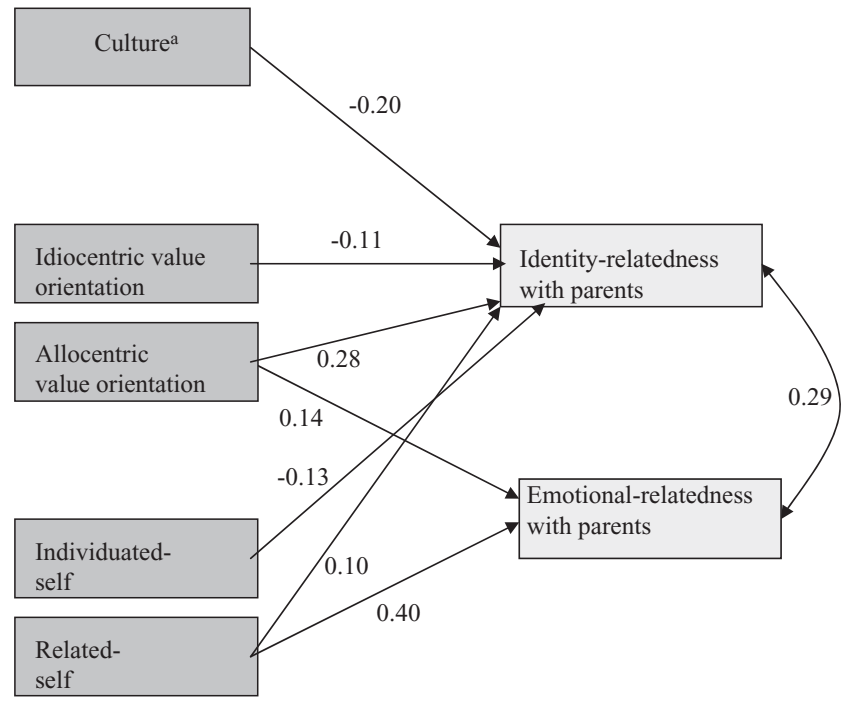

Figure 1 Significant predictors of emotional- and identity-relatedness with parents in the cross-cultural study; $\chi^{2}(3, \quad N=842)=16.43, \quad p<0.001, \quad \mathrm{GFI}=0.99$, $\mathrm{AGFI}=0.95, \mathrm{CFI}=0.99$; correlations between the variables considered are shown in Table 5. Standardized path coefficients are shown; all the path coefficients are significant at least at the 0.05 level. We did not add correlated errors between the predictors, but did so for Emotional- and Identity-Relatedness. ${ }^{a}$ Culture refers to Turkey (1) and the USA (2).

domains of relatedness. Triandis $(1989,1995)$ asserts that in all societies, the upper social classes are likely to be more individualistic than the lower social classes. Related studies generally showed that the more individualistic upper classes tend to emphasize independence, autonomy, selfdirection and self-reliance, while the more collectivistic lower classes tend to emphasize social control, obedience to parents, respect for authority, and socially appropriate behaviours which lead to conformity orientations (Kohn, 1969; Kohn \& Schooler, 1982; Scott, 2002; see HoffGinsberg \& Tardif, 1995 for a review). Accordingly, opportunities for occupational self-direction, which tend to be more available in upper class jobs, seem to be associated with increased intellectual functioning and self-directed orientation to self and society. Although a discussion of the literature on modernity concerning social class is beyond the limits of our paper, we can briefly conclude that socialstructural conditions, involving industrialization, tend to be associated with such psychological variables as being more open to new experiences, and adopting a less traditional and more rational outlook to life problems (for a review see Schooler, 1996).

In line with those conclusions, in the traditional segments of Turkish society, there appear to be 'fused and undifferentiated systems of relationships' (Fişek, 1984, p.
310). The ties with family members generally tend to be quite close and interdependent, but with increasing SES, Turkish people tend to express more individuated self-types (Imamoğlu, 1987, 2003; Imamoğlu \& KarakitapoğluAygün, 2004) and individualistic values (Imamoğlu \& Karakitapoğlu-Aygün, 1999, 2004; Karakitapoğlu-Aygün \& Imamoğlu, 2002). However, those studies demonstrated that these new preferences for individualism and autonomy among the upper SES people exist together with feelings of relatedness, in congruence with the BID model and other related suggestions (Imamoğlu, 1987; Kağıtçıbaş1, 1996; Karaday1, 1998; Karakitapoğlu-Aygün, 2004). On the basis of the above studies, we expected SES differences to be more pronounced for perceptions involving identities than for those of emotional closeness.

\section{Method}

Participants. A total of 353 (190 female, 163 male; mean age $=15.44$ years, $S D=0.75$, range $=14-18$ years $)$ high school students participated in the study. Of these, 186 (89 female, 97 male; mean age $=15.25$ years, $S D=0.78$, range $=14-18$ years) constituted the lower SES sample, and 167 (66 male, 101 female; mean age $=15.65$ years, $S D=0.66$, range $=14-17$ years) the upper SES sample. Two public high schools from poorer sections of Ankara were chosen for the lower SES sample, and two private schools from the more prosperous areas for the upper SES sample. As expected, the samples were different in terms of parental education. In the lower SES sample, most of the mothers were primary school graduates $(56 \%)$ or had no schooling (2\%); most of the fathers $(60 \%)$ were graduates of high school or junior high school; whereas in the upper SES sample, most of the fathers (89\%) and mothers (69\%) were university graduates or postgraduates.

Measures and procedure. The same scales were used as in the first study. Students again completed them in their classrooms. Cronbach's alpha values for self-directed and otherdirected value orientation scales were 0.80 and 0.86 in the upper SES sample and 0.77 and 0.79 in the lower SES sample. Alpha values for domains of relatedness are shown in Table 1.

\section{Results and discussion}

SES differences in domains of relatedness with parents. To investigate SES and gender differences in relatedness with mothers and fathers, a 2 (SES: upper, lower) $\times 2$ (gender: male, female) $\times 2$ (parent: mother, father) $\times 2$ (domain of relatedness: emotional-relatedness, identity-relatedness) analysis of variance (ANOVA) with repeated measures on the last two variables was conducted. Results indicated the 
Table 5 Intercorrelations among the variables

\begin{tabular}{|c|c|c|c|c|c|c|c|c|}
\hline & 1 & 2 & 3 & 4 & 5 & 6 & 7 & 8 \\
\hline \multicolumn{9}{|l|}{ Cross-cultural study $^{\dagger}$} \\
\hline 1. Culture & - & & & & & & & \\
\hline 2. Individuated-self & -0.02 & - & & & & & & \\
\hline 3. Related-self & $0.10 * *$ & 0.04 & - & & & & & \\
\hline 4. Idiocentric value orientation & -0.03 & $0.40 * * *$ & $0.15 * * *$ & - & & & & \\
\hline 5. Allocentric value orientation & $0.15^{* * *}$ & $-0.20 * * *$ & $0.39 * * *$ & $0.19 * * *$ & - & & & \\
\hline 6. Emotional-relatedness & -0.06 & -0.03 & $0.45 * * *$ & $0.09 * *$ & $0.29 * * *$ & - & & \\
\hline 7. Identity-relatedness & $-0.18 * * *$ & $-0.23 * * *$ & $0.16^{* * *}$ & $-0.09 * *$ & $0.29 * * *$ & $0.42 * * *$ & - & \\
\hline 8. Gender & -0.01 & $-0.09 * *$ & $-0.18 * * *$ & $-0.10 * *$ & -0.03 & -0.06 & -0.03 & \\
\hline$M$ & 1.51 & 3.83 & 4.12 & 4.40 & 3.78 & 6.52 & 4.39 & 1.43 \\
\hline$S D$ & 0.50 & 0.48 & 0.55 & 0.45 & 0.62 & 1.20 & 1.53 & 0.49 \\
\hline \multicolumn{9}{|l|}{ SES study } \\
\hline 1. SES & - & & & & & & & \\
\hline 2. Individuated-self & $0.25 * * *$ & - & & & & & & \\
\hline 3. Related-self & 0.00 & -0.04 & - & & & & & \\
\hline 4. Idiocentric value orientation & $0.18 * *$ & $0.42 * * *$ & $0.12 *$ & - & & & & \\
\hline 5. Allocentric value orientation & $-0.34 * * *$ & 0.00 & $0.38 * * *$ & $0.42 * * *$ & - & & & \\
\hline 6. Emotional-relatedness & $-0.14^{*}$ & -0.00 & $0.59 * * *$ & $0.15 * *$ & $0.43 * * *$ & - & & \\
\hline 7. Identity-relatedness & $-0.32 * * *$ & -0.08 & $0.29 * * *$ & 0.02 & $0.40 * * *$ & $0.44 * * *$ & - & \\
\hline 8. Gender & $-0.13^{*}$ & $-0.20 * * *$ & $-0.12 *$ & $-0.17 * *$ & -0.06 & -0.09 & -0.04 & \\
\hline$M$ & 1.47 & 3.72 & 3.92 & 4.10 & 3.90 & 7.23 & 5.76 & 1.46 \\
\hline$S D$ & 0.50 & 0.65 & 0.65 & 0.67 & 0.83 & 1.48 & 1.87 & 0.50 \\
\hline
\end{tabular}

$* p<0.05, * * p<0.01, * * * p<0.001$.

$\dagger 1$ = Turkey, 2 = USA; the effect of parental education was controlled.

1 = Lower SES, 2 = Upper SES.

SES, socioeconomic status.

main effects involving SES, $F_{1,349}=30.66, M S E=2.95$, $p<0.001, \eta^{2}=0.08$, parent, $F_{1,349}=21.53, M S E=2.02$, $p<0.001, \quad \eta^{2}=0.06$, and domain of relatedness, $F_{1,349}=242.07, M S E=3.08, p<0.001, \eta^{2}=0.41$ to be significant. According to SES main effect, lower SES respondents $(M=6.89)$ reported more relatedness with their parents than the upper SES respondents $(M=6.07)$. In terms of domain of relatedness, respondents reported more relatedness involving emotions than identities $(M=7.22$ and 5.74, respectively), replicating the cross-cultural findings. Furthermore, participants reported more relatedness with their mothers $(M=6.66)$ than fathers $(M=6.30)$, as in the cross-cultural study. These main effects were modified by significant interactions, as explained below.

First, SES $\times$ domain of relatedness interaction was significant, $F_{1,349}=16.28, M S E=3.08, p<0.001, \eta^{2}=0.05$. As shown in Table 1, lower SES students reported more relatedness in both domains than did the upper SES students, but the SES difference was greater for relatedness of identity than for emotional closeness. Thus, consistent with the idea of the dependency emphasis in the lower SES (Imamoğlu, 1987, 1991), our findings indicated that relatedness of identity differentiated more between the SES groups than did emotional closeness. Specifically, lower SES adolescents reported their identities to be more overlapping with their parents as compared to upper SES adolescents. In general, the lower social classes even in urban settings of Turkey tend to be more traditional, while the upper social classes tend to have more modern outlooks (Imamoğlu, 1987), in congruence with the related literature noted above (Schooler, 1996). Hence, this SES difference involving distinct or related identities may be important in indicating the direction of social change in the upper segments of Turkish culture toward more independence whereby adolescents begin to construe themselves as having a relatively distinct self-identity than their parents. However, in lower SES environments, where dependence of children to parents is more likely to be emphasized (Imamoğlu, 1987), self-other boundaries generally may be fuzzier.

Second, gender of the respondent-parent interaction was also found to be significant, $F_{1,349}=9.28, M S E=2.02$, $p<0.01, \eta^{2}=0.03$. As shown in Table 2, women displayed more relatedness with their mothers than their fathers, and more so than did men, while they seemed to be similarly related with fathers. Finally, parent $\times$ domain of relatedness 
interaction was significant, $F_{1,349}=11.07, M S E=0.99$, $p<0.01, \eta^{2}=0.03$. Follow-up analyses indicated that there were no differences between relatedness with mothers and fathers in the identity domain $(M \mathrm{~s}=5.83$ and 5.65 , respectively), but in the emotional domain, respondents reported more relatedness with mothers (7.48) than with fathers $(M=6.95, p<0.01)$.

Thus, according to gender-related results, women reported more relatedness with mothers relative to both fathers and their male counterparts, although the gender difference was not significant for fathers, as in the first study. Another significant difference was obtained involving mothers in that adolescents reported more emotional closeness with their mothers compared to fathers, while they perceived their identities as similarly related with both parents. These results are congruent with the related literature which associates femininity with relatedness and closeness, as noted earlier. However, it should be noted that the relatively low level of closeness with fathers should not be taken to imply separatedness. Instead, mean scores were quite high for both parents implying connected and close relationships with fathers, as well.

In the following analyses, only the effects involving selftypes and value orientations are reported, as in the first study.

Relatedness-domain differences involving self-types within and across SES groups. To explore differences in relatedness with parents as a function of SES and self-types, a 2 (SES: upper, lower) $\times 4$ (self-type: separated-patterned, separated-individuated, related-patterned, relatedindividuated) multivariate analysis of variance (MANOvA) was conducted using the two domains of relatedness as dependent variables. Results indicated the self-type multivariate effect to be significant, $F_{6,676}=17.49, p<0.001$, $\eta^{2}=0.13$. As shown in Table 3, both univariate effects were significant, indicating that students with related self-types reported more relatedness with their parents in both domains as compared to the students with separated selftypes. However, these results were further qualified by significant SES $\times$ self-type interaction, $F_{6,676}=2.90, p<0.01$, $\eta^{2}=0.03$. Univariate analyses reached significance only for emotional closeness, $F_{3,339}=3.52, M S E=1.58, p<0.05$, $\eta^{2}=0.03$, indicating that SES difference was significant only for adolescents with separated self-types who were emotionally less close to their parents at the upper SES compared to the lower, while those with related self-types did not differ. ${ }^{3}$

Thus, relatedness differences between self-construal types seemed to be greater for emotional closeness than for identities. As in the first study, adolescents with related rather than separated self-types reported more emotional closeness with parents independent of their level of individuation. Furthermore, this emotional closeness difference between the related and separated adolescents seemed to be greater at the upper relative to the lower SES because adolescents with separated self-types seemed to be less close with parents at the upper relative to lower SES; while those with related self-types did not differ. In terms of identityrelatedness, however, adolescents with related, rather than separated, self-types seemed to have more overlapping identities with parents, independent of their level of individuation and SES. However, regardless of self-types, the upper SES respondents perceived their identities as less related with parents than those in lower SES, as noted above. Thus, apart from feelings of closeness, the upper SES adolescents, in general, appeared to perceive their identities as relatively less merged with parents psychologically, relative to lower SES adolescents.

Relatedness-domain differences involving value orientations within and across SES groups. To explore differences in relatedness with parents as a function of SES and value orientations, a 2 (SES: lower, upper) $\times 2$ (idiocentric orientation: low, high) $\times 2$ (allocentric orientation: low, high) MANOVA was conducted using the two domains of relatedness as dependent variables. Results indicated the multivariate allocentric orientation effect to be significant, $F_{2,323}=11.59, p<0.001, \eta^{2}=0.07$. As shown in Table 4, the related univariate effects were significant for both domains of relatedness. Accordingly, respondents with high rather than low allocentric value orientation reported being both emotionally closer to their parents and as having more related identities independent of status groups.

Thus, in consistency with the results of the cross-cultural study, regardless of SES, the more allocentric (i.e. in terms of endorsing other-directed values) adolescents reported more relatedness in both domains (i.e. the allocentric value orientation seemed to have a similar impact on relatedness involving both emotions as well as identities). However, the idiocentric value orientation (i.e. in terms of holding selfdirected values) appeared to be independent of relatedness with parents.

Overall analysis of key variables. Based on the correlations shown in Table 5, the degree to which SES, relatedness (of self-construals), and allocentrism predict emotional- and identity-relatedness was tested by using LISREL. Allocentrism, and relatedness appeared as significant predictors of both identity-relatedness (respective beta coefficients being 0.26 and 0.18 ) and emotional-closeness (respective beta coefficients being 0.24 and 0.50 ), whereas SES predicted only identity-relatedness (beta coefficient $=-0.21), \quad \chi^{2}(1, N=353)=2.29, \quad p<0.13, \quad$ GFI $=$ 1.00 , AGFI $=0.96, \mathrm{CFI}=1.00 .{ }^{4} \mathrm{In}$ a preliminary analysis, individuation and idiocentrism were also entered into the model; however, unlike the first study, those variables did not appear as significant predictors, suggesting that, at least for Turkey, one's level of individuation and idiocentric 
value orientation do not predict less overlapping identities with parents during adolescence but at later ages, as was observed in our university sample. However, in congruence with the results of the first study, relatedness and allocentrism were found as the strongest predictors of emotional and identity-relatedness, respectively. The general implications of these findings together with the cross-cultural ones are considered further in the section below.

\section{General discussion}

Both Turkish and American respondents reported more emotional- than identity-relatedness, reflecting the importance of emotional closeness with parents as a basic need across cultures (Ainsworth, 1972; Bowlby, 1988; Baumeister \& Leary, 1995). However, unlike emotional relatedness with parents, which seemed to be less variable, the degree to which young people perceived their identities as overlapping with their parents appeared to be a more differentiating dimension between cultural and, particularly, SES groups. American university students, compared to their Turkish counterparts, as well as Turkish upper SES adolescents compared to lower, perceived their identities as less overlapping with their parents. Thus, present findings imply that identity-relatedness may be more relevant to the I-C distinction, whereas emotional relatedness may not be so, at least when parents are targeted.

However, our results also implied that one should be rather cautious in making such cross-cultural generalizations. An important aspect of the present paper was to consider not only cross-cultural but also within-culture variations in the two domains of relatedness with parents. Differences in relatedness with parents, in terms of selftypes and value-orientations in both societies, and SES groups in Turkey, provided converging evidence for significant within-culture variation in relatedness. In fact, there seemed to be more within-culture variation in relatedness than across cultures, as considered below.

Specifically, in both individualist and collectivist contexts, there appeared to be quite a variation especially in emotional closeness with parents, associated with selftypes. Across contexts, those with more related self-types, as suggested by the BID model, were more likely to be emotionally close to their parents regardless of their level of individuation which seemed to impact only relatedness of identities with parents (among university students). In congruence with attachment theory (Ainsworth, 1972; Bowlby, 1988), these results suggest that emotional closeness with parents may be associated with the particular self-type of respondents (involving the relational self-orientation), which may be influenced more by the characteristics of their immediate family settings (Imamoğlu, 2003), rather than the characteristics of the broader cultural and status contexts.
In terms of value orientations, our results indicated that, across cultural and SES contexts, the more, rather than the less, allocentric respondents tended to perceive themselves as more related with their parents in both domains. A weaker trend was obtained for the more, rather than the less, idiocentric university students to have relatively less related identities. However, the latter finding should not be understood to imply that those idiocentrically oriented university students were emotionally less close with their parents because, in general, emotional relatedness appeared to be independent of the idiocentric value orientation (as of individuation). In fact, there was a weak trend for the more, rather than the less, idiocentric university students to report being emotionally closer to their parents. Thus, the present findings imply that although relatedness (in both domains) with parents generally seems to be associated with allocentrism, it should not be considered as opposing idiocentrism, as also suggested by past research (Oyserman, 1993; Singelis, 1994; Kashima et al., 1995).

In summary, as indicated by our overall results of SEM analyses, relational-self and allocentric-value orientations significantly predicted emotional closeness with parents across contexts, whereas identity-relatedness was predicted positively by both allocentric-value and relational-self orientations, and negatively by both idiocentric value- and individuational self-orientations (the latter two being significant only for the university sample), as well as, by the individualist nature of cultural or SES contexts. Thus, allocentric-value and related-self orientations appeared as the only variables positively predicting both domains of relatedness. It can be speculated that, in both cultures, such allocentric respondents with related self-construals might have developed in family contexts referred to as integrative by the BID model, where members are "expected to be integrated to their families, or other groups, not only in terms of affective attachments but also in terms of cognitive or ideational similarities' (Imamoğlu, 2003; p. 374). In fact, respondents with the most integrated (i.e. related-patterned) self-type were the only group that scored high in both domains of relatedness with parents across cultures, in contrast to those with the most differentiated (i.e. separated-individuated) self-type, in congruence with the BID model. As noted above, our SEM model also suggested that a related self-construal, considered independently of individuation, seems to be a relatively stronger predictor of emotional, than of identity, relatedness whereas individuation seems to predict only identity-relatedness but to be distinct from emotional relatedness with parents. Thus, in congruence with past findings, noted earlier (Imamoğlu, 2003; Imamoğlu, 2005; Imamoğlu \& Imamoğlu, in press), relational and individuational self-orientations tend to be associated with relatively distinct domains of relatedness with parents. Finally, as noted, our SEM analyses suggested that the collectivist nature of cultural or SES contexts may 
be more likely to predict identity-relatedness with parents, rather than emotional closeness.

In terms of gender, in both studies, consistent gender differences were obtained. As expected, women appeared to be more related with their mothers than men did. However, although consistent across contexts, the impact of this difference seemed to be quite weak. In fact, gender did not appear as a significant predictor of relatedness with parents in our overall SEM analyses.

\section{Limitations and conclusions}

Before concluding, we need to note some limitations of our studies. First, an important limitation is that our crosscultural data are limited to university students and SESrelated Turkish data to high school students. Our results cannot be generalized to Turkish and American societies, and lower and upper SES Turkish segments at large. As university students across cultures tend to represent the better-educated, middle-upper SES groups (Hofstede, 1980; Triandis, 1995; Freeman, 1997), our cross-cultural results need to be viewed with this limitation in mind. Furthermore, all data consist of students' self-reports and perceptions. For instance, when reference is made to 'emotional closeness', what is meant is 'emotional closeness as perceived by' the respondent. Although using only adolescents' reports could be a limitation, we considered adolescents' own perceptions to be more relevant to our present purposes. In this regard, Heine and colleagues' (Heine, Lehman, Peng, \& Greenholtz, 2002) criticisms regarding the usage of subjective Likert scales in cross-cultural comparisons may be said to be relevant to our first study as well. That is, these psychologists argue that because people from different cultures use different reference groups, a response option of, for instance, 'strongly agree' would have a different meaning across cultures and, hence, their ratings may be influenced in the direction that reduces the magnitude of the measured cultural difference. However, the PRS, which we used to measure our dependent variables of emotional- and identityrelatedness with parents, consisted of not verbal response options but Venn-diagrams, in line with Aron et al. (1991). Although the respondents' ratings on the PRS were subjective, they might have been less confounded by the reference group effect due to the graphic and, hence, more objective, nature of the response options as compared to a regular Likert scale. Another limitation is that relatedness was measured only in relation to parents. Other studies in the literature provide evidence that people relate differently to different in-groups, such as relatives, friends, or strangers. (Rhee et al., 1996; Göregenli, 1997; Uleman et al., 2000). These studies pointed to the variability in relatedness depending on the social context or target in-group. Future studies need to investigate whether present findings can be generalized to other family or in-group members, and to other cultures. Also, in the present study, idiocentric and allocentric value orientations have been considered only in terms of self- or other-directedness. Future studies should consider using other measures of I-C or value orientations.

In spite of the above-noted limitations, our findings made important contributions to understanding relatedness with parents across and within cultures. First, our findings suggest that relationality needs to be considered in more specific terms than the I-C literature indicates, at least when parents are targeted. It seems important to differentiate between emotional and identity domains of relatedness with parents, as only the latter seems to be relevant to the I-C differentiation. In view of related findings which emphasize the role of expectations in cultural differences (Imamoğlu \& Karakitapoğlu-Aygün, 2006), it can be said that normative expectations about having distinct or related identities may be more important than emotional closeness in differentiating between individualist and collectivist contexts. Thus, I-C theorists' references to cultural differences in relatedness may be understood as implicating expectations regarding relatedness of identities rather than emotional closeness. Second, although relatedness with parents, regardless of its domain, generally seems to be associated with allocentrism in both cultures, it should not be assumed to be opposing idiocentrism, as is often implied by the related literature. For example, Kağıtçıbaşı (1996), who seems likely to understand relatedness in a way similar to our identity domain, has suggested to use relational I-C to refer to "the distinction between a separated, self-contained self and a relational self, where the self's boundaries and self-other relations come to the fore', and has asserted relational individualism to be 'akin to separateness and relational collectivism to relatedness' ( $p$. 181). As noted, although relatedness of identities was found to differentiate between I-C contexts, the present findings suggest that one needs to be cautious in tending to pit individualism against collectivism and hence regard it as 'akin to separateness'. Although Americans from an individualist context (relative to Turks from a collectivist context), as well as upper SES (relative to lower SES) Turkish adolescents, and the more (rather than the less) idiocentric university students in both cultures tended to perceive their identities as relatively less overlapping with their parents, the related impact factors were generally low, and all groups perceived their identities as somewhat related with their parents. In fact, those groups seemed less likely to differ significantly in terms of the emotional domain of relatedness. Hence, the present findings suggest that, at least when relatedness with parents is concerned, allocentric and idiocentric orientations should not be regarded as opposing each other, and relationality, although associated with the former, should be studied separately from the latter, as has been suggested by earlier 
findings (Kashima et al., 1995; Oyserman et al., 2002; Imamoğlu \& Karakitapoğlu-Aygün, 2004). Third, the present findings suggest that the impact of within-culture differences in relatedness with parents as a function of self-types, value orientations, or SES may be greater than that of culture. Culture's impact on even relatedness in the identity domain, although significant, was low. Hence, as suggested by recent findings, one should be cautious not to represent culture almost as a 'uniform' worn by everyone belonging to that culture (Imamoğlu \& KarakitapoğluAygün, 2006). Fourth, patterns of relatedness with parents associated with different self-types, suggested by the BID model, as well as with idiocentric and allocentric value orientations seem to be similar across cultural contexts. Thus, the present findings suggest that contextual differences and similarities in relatedness with parents need to be considered in more complex terms than has been implied by the global formulations of the I-C framework.

\section{Acknowledgements}

We express our appreciation to Middle East Technical University and Turkish Academy of Sciences for the partial support they have provided.

\section{End notes}

1. The results of the analyses comparing Euro-American and other minority groups on the dependent variables indicated that groups, in general, did not differ from each other.

2. Gender, which did not appear as a significant predictor in either study, was dropped from the model.

3. A figure showing the related means may be obtained from the authors.

4. The related path diagram may be obtained from the authors.

\section{References}

Ainsworth, M. D. S. (1972). Attachment and dependency: A comparison. In: J. L. Gewirtz, ed. Attachment and Dependency, pp. 97-137. Washington, DC: Winston \& Sons.

Aron, A., Aron, E. N. \& Smollan, D. (1992). Inclusion of other in the self scale and the structure of interpersonal closeness. Journal of Personality and Social Psychology, 63, 596612.

Aron, A., Aron, E. N., Tudor, M. \& Nelson, G. (1991). Close relationships as including other in the self. Journal of Personality and Social Psychology, 60, 241-253.

Bandura, A. (2001). Social cognitive theory: An agentic perspective. Annual Review of Psychology, 52, 1-26.

Baumeister, R. \& Leary, M. R. (1995). The need to belong: Desire for interpersonal attachments as a fundamental human motivation. Psychological Bulletin, 117, 497-529.
Bowlby, J. (1988). A Secure Base: Clinical Applications of Attachment Theory. London: Routledge.

Chodorow, N. (1978). The Reproduction of Mothering: Psychoanalysis and the Sociology of Gender. Berkeley, CA: University of California Press.

Cross, S. E. \& Madson, L. (1997). Models of the self: Selfconstruals and gender. Psychological Bulletin, 122, 5-37.

Cross, S. E., Bacon, P. L. \& Morris, M. L. (2000). The relationalinterdependent self-construal and relationships. Journal of Personality and Social Psychology, 78, 791-808.

Fijneman, Y. A., Willemsen, M. E. \& Poortinga, Y. H. in cooperation with Erelcin, F. G., Georgas, J., Hui, H. C., Leung, K. \& Malpass, R. S. (1996). Individualism-collectivism: An empirical study of a conceptual issue. Journal of CrossCultural Psychology, 27, 381-401.

Fişek, G. O. (1984). Psychopathology and the Turkish family: A family systems theory analysis. In: Ç. Kağıtçıbaşı, ed. Sex Roles, Family and Community in Turkey, pp. 295-321. Bloomington, IN: Indiana University.

Frank, S. J., Avery, C. B. \& Laman, M. S. (1988). Young adult's perceptions of their relationships with their parents: Individual differences in connectedness, competence and emotional autonomy. Developmental Psychology, 24, 729-737.

Freeman, M. A. (1997). Demographic correlates of individualism and collectivism: A study of social values in Sri Lanka. Journal of Cross-Cultural Psychology, 28, 321-341.

Gabriel, S. \& Gardner, W. L. (1999). Are there 'his' and 'hers' types of interdependence? The implications of gender differences in collective versus relational interdependence for affect, behavior, and cognition. Journal of Personality and Social Psychology, 77, 642-655.

Geertz, C. (1973a). Religion as a cultural system. The Interpretation of Cultures: Selected Essays by Clifford Geertz, pp. 87-125. New York: Basic.

Geertz, C. (1973b). Ritual and social change: A Javanese example. The Interpretation of Cultures: Selected Essays by Clifford Geertz, pp. 142-169. New York: Basic.

Georgas, J., Mylonas, K., Bafiti T., et al. (2001). Functional relationships in the nuclear and extended family: A 16-culture study. International Journal of Psychology, 36, 289-300.

Gezici, M. \& Güvenç, G. (2003). Çalışan kadınların ve ev kadınlarının benlik algısı ve benlik kurgusu açısından karşılaştırılmas1 [Self perceptions and self-construals of women in relation to employment and domestic status]. Turkish Journal of Psychology, 18, 1-17 (in Turkish).

Gilligan, C. (1982). In a Different Voice: Psychological Theory and Women's Development. Cambridge, MA: Harvard University Press.

Göregenli, M. (1997). Individualist and collectivist tendencies in a Turkish sample. Journal of Cross-Cultural Psychology, 28, 787-794.

Güler, A. (2004). Relationship between self-construals and future time orientations. Unpublished Master's Thesis, Middle East Technical University, Ankara, Turkey.

Heine, S. J., Lehman, D. R., Peng, K. \& Greenholtz, J. (2002). What's wrong with cross-cultural comparisons of subjective Likert scales? The reference-group effect. Journal of Personality and Social Psychology, 82, 903-918. 
Hoff-Ginsberg, E. \& Tardif, T. (1995). Socioeconomic status and parenting. In: M. H. Bornstein, ed. Handbook of Parenting: Biology and Ecology of Parenting, Vol. 2, pp. 161-188. Hillsdale, NJ: Lawrence Erlbaum.

Hofstede, G. (1980). Culture's Consequences: International Differences in Work-Related Values. Beverly Hills, CA: Sage.

Imamoğlu, E. O. (1987). An interdependence model of human development. In: Ç. Kağıtçıbaşı, ed. Growth and Progress in Cross-Cultural Psychology, pp. 138-145. Lisse: Swets and Zeitlinger.

Imamoğlu, E. O. (1991). Çocuğun aile içinde yetişme ortamı ve toplumsallaşması [Socialization of the child in the family context]. In: I. Sezal, M. Mete, M. Isen, \& H. Karpuz, eds. Türkiye Aile Ansiklopedisi, Vol. 1, pp. 236-240. Ankara: Türkiye Yazarlar Birliği Vakfi (in Turkish).

Imamoğlu, E. O. (1995). Değişim sürecinde aile: Evlilik ilişkileri, bireysel gelişim ve demokratik değerler [Family in transition: Marital relations, individual development, and democratic values]. In: The Turkish Family Research Association, eds. 1994 Aile Kurultayı, pp. 33-51. Ankara: Aile Araştırma Kurumu (in Turkish).

Imamoğlu, E. O. (1998). Individualism and collectivism in a model and scale of balanced differentiation and integration. Journal of Psychology, 132, 95-105.

Imamoğlu, E. O. (2002). Doğu-Batı kavşağında benlik: Dengeli ayrışma-bütünleşme modeli [Self at East-West crossroads: The balanced integration- differentiation model]. Invited speech, The 12th Turkish Psychology Congress; September 2002, Ankara, Turkey (in Turkish).

Imamoğlu, E. O. (2003). Individuation and relatedness: Not opposing, but distinct and complementary. Genetic, Social, and General Psychology Monographs, 129, 367-402.

Imamoğlu, E. O. (2006). Dengeli yetişme ortamı ve benlik modeli: 1970'lerden 2000'lere bir araştırma öyküsü [A model of balanced developmental context and self: Story of a research program from 1970s to 2000s]. Invited speech, The 14th Turkish Psychology Congress; September 2006, Ankara, Turkey (in Turkish).

Imamoğlu, E. O. \& Imamoğlu, V. (1992). Life situations and attitudes of the Turkish elderly toward institutional living within a cross-cultural perspective. Journal of Gerontology: Psychological Sciences, 47, 102-108.

Imamoğlu, E. O. \& Imamoğlu, V. (1996). Insan, Evi ve Çevresi [Individuals, Their Homes, and Environments]. Ankara: Başbakanlık Toplu Konut Idaresi Yayını (in Turkish).

Imamoğlu, E. O., \& Imamoğlu, S. (in press). Relationships between attachment security and self-construal orientations. The Journal of Psychology: Interdisciplinary and Applied.

Imamoğlu, E. O. \& Karakitapoğlu-Aygün, Z. (1999). 1970lerden 1990lara değerler: Üniversite düzeyinde gözlenen zaman, kuşak ve cinsiyet farklılıkları [Value preferences from 1970s to 1990s: Cohort, generation and gender differences at a Turkish University]. Turkish Journal of Psychology, 14, 1-22 (in Turkish)

Imamoğlu, E. O. \& Karakitapoğlu-Aygün, Z. (2004). Selfconstruals and values in different cultural and socioeconomic contexts. Genetic, Social, and General Psychology Monographs, 130, 277-306.
Imamoğlu, E. O. \& Karakitapoğlu-Aygün, Z. (2006). Actual, ideal and expected relatedness with parents across and within cultures. European Journal of Social Psychology, 36, 721-745.

Imamoğlu, E. O., Küller, R., Imamoğlu, V. \& Küller, M. (1993). The social psychological worlds of Swedes and Turks in and around retirement. Journal of Cross-Cultural Psychology, 24, 26-41.

Imamoğlu, S. (2005). Secure exploration: Conceptualization, types, and relationships with secure attachment, self-construals, and other self-related variables. Unpublished PhD Dissertation, Middle East Technical University, Ankara, Turkey.

Jordan, J. V. (1997). The relational model is a source of empowerment for women. In: M. R. Walsh, ed. Women, Men and Gender: Ongoing Debates. New Haven, CT: Yale University Press.

Kağıtçıbaşı, Ç. (1996). The autonomous-relational self: A new synthesis. European Psychologist, 1, 180-186.

Kağıtçıbaşı, Ç. (2005). Autonomy and relatedness in cultural context: Implications for self and family. Journal of CrossCultural Psychology, 36, 403-422.

Karadayı, F. (1998). Ilişskili Ōzerklik: Kavramı, Ōlcülmesi, Gelişimi ve Toplumsal Onemi [Related Autonomy: Conceptualization, Measurement, Development, and Societal Importance]. Adana: Çukurova Üniversitesi Basımevi (in Turkish).

Karakitapoğlu-Aygün, Z. (2004). Self, identity, and emotional well-being among Turkish University students. Journal of Psychology, 138, 457-478.

Karakitapoğlu-Aygün, Z. \& Imamoğlu, E. O. (2002). Value domains of Turkish adults and University students. Journal of Social Psychology, 142, 333-351.

Kashima, Y., Yamaguchi, K. Y., Kim, U., Choi, S. C., Gelfand, M. J. \& Yuki, M. (1995). Culture, gender and self: A perspective from individualism-collectivism research. Journal of Personality and Social Psychology, 69, 925-937.

Kohn, M. (1969). Class and Conformity: A Study in Values. Homewood, IL: Dorsey.

Kohn, M. \& Schooler, C. (1982). Job conditions and personality: A longitudinal assessment of their reciprocal effects. American Journal of Sociology, 87, 1257-1283.

Kurt, A. (2002a). A comparison of three self-construal conceptualizations with respect to issues of culture and gender. Poster Presented at the Annual Convention of the Society for Personality and Social Psychology; February, 2002, Savannah, GA.

Kurt, A. (2002b). Autonomy and relatedness: A comparison of Canadians and Turks. Paper Presented at the Annual Convention of Canadian Psychological Association; June 2002, Vancouver, BC.

Li, H. Z. (2002). Culture, gender and self-close other(s) connectedness in Canadian and Chinese samples. European Journal of Social Psychology, 32, 93-104.

Lykes, M. B. (1985). Gender and individualistic versus collectivist bases for notions about the self. Journal of Personality, 53, 357-383.

Markus, H. R. \& Kitayama, S. (1991). Culture and the self: Implications for cognition, emotion and motivation. Psychological Review, 98, 224-253.

Markus, H. R. \& Kitayama, S. (2003). Models of agency: Sociocultural diversity in the construction of action. In: V. M. 
Berman \& J. J. Berman, eds. Nebraska Symposium on Motivation: Cross-Cultural Differences in Perspectives on the Self, Vol. 49, pp. 1-57. Lincoln, NE: University of Nebraska Press.

Matsumoto, D. (1999). Culture and self: An empirical assessment of Markus and Kitayama's theory of independent and interdependent self-construals. Asian Journal of Social Psychology, 2, 289-310.

Mellor, S. (1989). Gender differences in identity formation as a function of self-other relations. Journal of Youth and Adolescence, 18, 361-375.

Miller, J. G. (2003). Culture and agency: Implications for psychological theories of motivation and social development. In: V. M. Berman \& J. J. Berman, eds. Nebraska Symposium on Motivation: Cross-Cultural Differences in Perspectives on the Self, Vol. 49, pp. 59-99. Lincoln, NE: University of Nebraska Press.

Neff, K. (2003). Understanding how universal goals of independence and interdependence are maintained within particular cultural contexts. Human Development, 46, 312-318.

Olver, R. R., Aries, E. \& Batgos, J. (1989). Self-other differentiation and the mother-child relationship: The effects of sex and birth order. Journal of Genetic Psychology, 150, 311-321.

Oyserman, D. (1993). The lens of personhood: Viewing the self and others in a multicultural society. Journal of Personality and Social Psychology, 65, 993-1009.

Oyserman, D., Coon, H. M. \& Kemmelmeier, M. (2002). Rethinking individualism and collectivism: Evaluation of theoretical assumptions and meta-analyses. Psychological Bulletin, 128, 3-72.

Rhee, E., Uleman, J. S. \& Lee, H. K. (1996). Variations in collectivism, and individualism by in-group and culture: Confirmatory factor analyses. Journal of Personality and Social Psychology, 71, 1037-1054.

Ryan, R. M. (1991). The nature of the self in autonomy and relatedness. In: J. Strauss \& G. R. Goethals, eds. The Self: Interdisciplinary Approaches, pp. 208-238. New York: Springer-Verlag.

Ryan, R. M. \& Deci, E. L. (2000). Self-determination theory and the facilitation of intrinsic motivation, social development and well-being. American Psychologist, 55, 68-78.

Ryan, R. M. \& Lynch, J. H. (1989). Emotional autonomy versus detachment: Revisiting the vicissitudes of adolescence and young adulthood. Child Development, 60, 340-356.

Schooler, C. (1996). Cultural and social-structural explanations of cross-national psychological differences. Annual Review of Sociology, 22, 323-349.

Schwartz, S. H. (1992). Universals in the content and structure of values. In: M. Zanna, ed. Advances in Experimental Psychology, Vol. 25, pp. 1-62. New York: Academic Press.
Schwartz, S. H., Melech, G., Lehmann, A., Burgess, S., Harris, M. \& Owens, V. (2001). Extending the cross-cultural validity of the theory of basic human values with a different method of measurement. Journal of Cross-Cultural Psychology, 32, 519542.

Scott, J. (2002). Social class and stratification in late modernity. Acta Sociologica, 45, 23-35.

Singelis, T. M. (1994). The measurement of independent and interdependent self-construals. Personality and Social Psychology Bulletin, 20, 580-591.

Sinha, D. \& Tripathi, R. C. (1994). Individualism in a collectivist culture: A case of coexistence of opposites. In: U. Kim, H. C. Triandis, Ç. Kağıtçıbaşı, S. C. Choi \& G. Yoon, eds. Individualism and Collectivism: Theory, Method and Applications, pp. 123-136. Thousand Oaks, CA: Sage.

Sunar, D. (1999). Culture and gender influences on self-concept and the bases of self-esteem: Four Turkish studies. In: W. J. Lonner, ed. Merging Past, Present and Future in CrossCultural Psychology: Selected Papers from the 14th International Congress of the International Association for Cross-Cultural Psychology, pp. 387-395. Lisse: Swets \& Zeitlinger.

Takano, Y. \& Osaka, E. (1999). An unsupported common view: Comparing Japan and the U.S. on individualism/collectivism. Asian Journal of Social Psychology, 2, 311-341.

Triandis, H. C. (1989). The self and social behavior in differing cultural contexts. Psychological Review, 96, 506-520.

Triandis, H. C. (1995). Individualism and Collectivism. Boulder, CO: Westview.

Triandis, H. C., Bontempo. R., Villareal, M. J., Asai, M. \& Lucca, N. (1988). Individualism and collectivism: Cross-cultural perspectives on self-in-group relationships. Journal of Personality and Social Psychology, 54, 323-338.

Uleman, J., Rhee, E., Bardoliwalla, N., Semin, G. \& Toyama, M. (2000). The relational self: Closeness to ingroups depends on who they are, culture and the type of closeness. Asian Journal of Social Psychology, 3, 1-17.

Van den Heuvel, K. \& Poortinga, Y. H. (1999). Resource allocation by Greek and Dutch students: A test of three models. International Journal of Psychology, 34, 1-13.

Van Ijzendoorn, M. H. \& Sagi, A. (1999). Cross-cultural patterns of attachment: Universal and contextual dimensions. In: J. Cassidy \& P. R. Shaver, eds. Handbook of Attachment: Theory, Research, and Clinical Applications, pp. 434-456. New York: Guilford Press.

Youniss, J. \& Ketterlinus, R. D. (1987). Communication and connectedness in mother and father-adolescent relationships. Journal of Youth and Adolescence, 16, 265-280. 